\title{
Research Progress of Online Review Content Based on Interpretation Level Theory
}

\author{
Xu Yaping 1,*, Liang Qingyu ${ }^{2}$ \\ ${ }^{1}$ Xu Yaping, ${ }^{2}$ Liang Qingyu, Lanzhou University of Technology, 730050 Lanzhou, Gansu, China
}

\begin{abstract}
Online reviews have become the main method of information dissemination, an important factor in consumer purchase decisions, and an important basis for merchants to improve their services. It has attracted the attention of scholars. The application of explanation level theory in consumer behavior research has begun to show an increasing trend. After sorting out the existing literature, it is found that the online review literature based on the interpretation level theory mainly studies the impact on consumers' purchase intention from the three perspectives of reviewers, review content and review readers. Among them, the content of comments is mostly discussed in terms of comment type and information quality, but it has not been systematically summarized. Using the literature review method, based on the interpretation level theory, the review type, information quality, interpretation type and perceived similarity are analyzed from the perspective of review content, and the existing literature is sorted in order to provide references for future research.
\end{abstract}

\section{Introduction}

Online reviews refer to consumers posting positive or negative opinions about the product on the website [1]. The survey found that $80 \%$ of $18-34$ year-olds have posted online comments, and the trust and recommendation ratio for online comments is as high as $91 \%$ [2]. At present, research on online comment content mainly focuses on language text analysis, such as the use of text mining technology to analyse comment content feature indicators [3], emotional polarity [4], the number of negative words, etc. [5]. The availability of information content will enhance people's decision-making confidence [6]. The indepth influence mechanism of comment content on consumers' purchase intention is more worthy of excavation and analysis.

Research scholars abstract the distance dimension related to the interpretation level as psychological distance [7]. Existing research has not carried out a comprehensive and systematic combing and summarization of relevant literature. Retrieve and select the literature on review content and interpretation level theory, and summarize the current research status and key issues in this field from the four perspectives of review type, review quality, interpretation type and perceived similarity, in order to provide reference for further research in the future And reference.

\section{Statistical analysis of online review content}

With reference to the practice of Li Ang et al. [8], the CNKI academic trend query with "comment content" as the key word found that from 2009 to 2019, the research enthusiasm for comment content at home and abroad has generally shown an increasing trend. The details are shown in Figure 1.

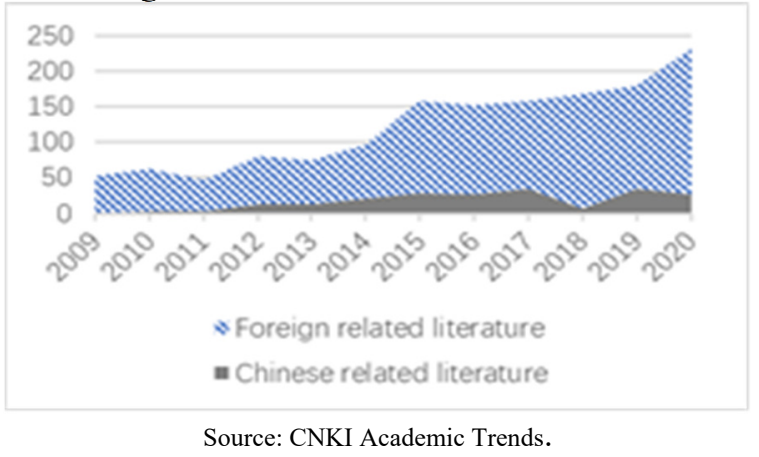

Fig. 1. 2009-2019 Academic attention of review content

By collecting and sorting out the research literature on comment content based on the interpretation level theory, it is found that the research content mainly includes four aspects: comment type, comment quality, interpretation type and perceived similarity, as shown in Table 1.

Table 1 Review content research literature based on the interpretation level theory

\begin{tabular}{|c|c|c|}
\hline Author (year) & Article title & Review content \\
\hline Zhang Meng et al. (2012) & $\begin{array}{c}\text { The Impact of Hotel Online Review Content } \\
\text { Features on Consumers' Purchase Intention -- } \\
\text { An Experimental Study Based on Time }\end{array}$ & Perceived similarity \\
\hline
\end{tabular}

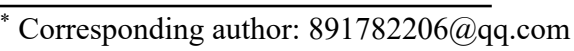




\begin{tabular}{|c|c|c|}
\hline & Distance and Social Distance Scenes & Comment type \\
\hline Huang Liqiang et al. (2013) & $\begin{array}{c}\text { Research on Consumers' Evaluation } \\
\text { Mechanism of Product Reviews }\end{array}$ & Explanation type \\
\hline Zhou Meihua et al. (2015) & $\begin{array}{c}\text { The Influence of Online Reviews on } \\
\text { Consumers' Purchase Intention: The } \\
\text { Mediating Role of Psychological Distance }\end{array}$ & $\begin{array}{c}\text { Comment on the quality } \\
\text { Perceived similarity }\end{array}$ \\
\hline Rong Chen et al. (2016) & $\begin{array}{c}\text { How Online Reviews Are More Useful -- The } \\
\text { Influence of Online Reviews Based on } \\
\text { Interpretive Types on Consumer Buying } \\
\text { Decisions and Boundary Conditions }\end{array}$ & Explanation type \\
\hline Wang Xuhui, et al. (2017)" & $\begin{array}{c}\text { "Explaining Behavior or Explaining } \\
\text { Response" : The Influence of Online Reviews } \\
\text { Based on Explaining Types on Consumer } \\
\text { Buying Decisions and Boundary Conditions }\end{array}$ & Comment type \\
\hline Li Qigeng et al. (2017) & $\begin{array}{c}\text { The Influence of Online Review Information } \\
\text { Characteristics of Service Products on Review } \\
\text { Perceived Usefulness. }\end{array}$ \\
\hline Li Baoku, et al. (2019) making. & $\begin{array}{c}\text { The influence of explanatory types on } \\
\text { perceived usefulness of online reviews from } \\
\text { the perspective of two-stage decision }\end{array}$ & Explanation type \\
\hline Qin Zhang et al. (2019) Difference. & $\begin{array}{c}\text { Shopping for Others: How Persuasive Online } \\
\text { Reviews Make a Difference }\end{array}$ & Perceived similarity \\
\hline
\end{tabular}

\section{Research progress of explanatory level and psychological distance dimension}

The interpretation level theory was first proposed by Trope and Liberman, which refers to the mental representation of the object by the cognitive subject. The level of explanation will change with the change of psychological distance. When the psychological distance is close, people will use a low level of explanation, and when the psychological distance is far away, people will use a high level of explanation [7].

Table 2 Interpretation level and psychological distance

\begin{tabular}{|c|c|c|}
\hline $\begin{array}{c}\text { Interpretation } \\
\text { level }\end{array}$ & $\begin{array}{c}\text { Psychological } \\
\text { distance } \\
\text { dimension } \\
\end{array}$ & Characteristic \\
\hline \multirow{3}{*}{$\begin{array}{l}\text { High level of } \\
\text { interpretation }\end{array}$} & $\begin{array}{c}\text { Long time } \\
\text { distance }\end{array}$ & \multirow{3}{*}{$\begin{array}{c}\text { Focus on core features } \\
\text { and abstract } \\
\text { information }\end{array}$} \\
\hline & $\begin{array}{c}\text { Long space } \\
\text { distance }\end{array}$ & \\
\hline & $\begin{array}{c}\text { Far social } \\
\text { distance }\end{array}$ & \\
\hline \multirow{3}{*}{$\begin{array}{l}\text { Low level of } \\
\text { interpretation }\end{array}$} & Short distance & \multirow{3}{*}{$\begin{array}{l}\text { Focus on non-core } \\
\text { features and specific } \\
\text { details }\end{array}$} \\
\hline & $\begin{array}{c}\text { Close space } \\
\text { distance }\end{array}$ & \\
\hline & $\begin{array}{l}\text { Close social } \\
\text { distance }\end{array}$ & \\
\hline
\end{tabular}

\subsection{Time distance dimension}

$\mathrm{Li}$ Zehua discussed the time interval between comments [9]. Li Qigeng found that time distance and comment valence have an interactive effect on perceived usefulness and purchase intention [10]. In summary, it can be seen that time distance plays an important role in the value perception of online reviews.

\subsection{Social distance dimension}

Zhou Meihua and others found that consumers buy products for themselves, have a closer psychological distance, and pay more attention to the feasibility of the product [11]. According to $\mathrm{Li}$ Baoku's research, consumers will be influenced by commentators with similar social identities [12]. Zhang Qin believes that interpersonal similarity is a manifestation of the social dimension of psychological distance [13]. In research, social distance is usually inseparable from similarity.

\subsection{Spatial distance dimension}

The spatial distance dimension refers to the individual's perception of the distance of the space [14]. Che Cheng found that word-of-mouth information with a low level of interpretation is more useful to consumers when the spatial distance is relatively close [15]. At present, there are few researches on spatial distance, and the relationship between spatial distance and spatial distance has not been discussed in detail in terms of comment type, information quality, interpretation type, etc. of comment content.

\subsection{Hypothetical (probabilistic) dimensions}

The hypothetical (probability) dimension refers to the degree of consumer perception of the likelihood of an event [14]. Existing studies have very few studies on the hypothetical dimension, mainly for the following two reasons. The first discussion about hypothesis usually shifts to the other three distance dimensions. The second hypothesis has the highest degree of abstraction and is difficult to measure. 


\section{The application of interpretation level theory to online review content and its impact}

Based on the interpretation level theory, the impact of online review content on consumer purchase behavior can be sorted out from four categories: review type, information quality, interpretation type, and perceived similarity.

\subsection{Comment type}

For different research purposes, the existing literature has different classifications of review types. Li Baoku divides the comment types into identification comments and instrumental comments according to the different interests of consumers [12]. According to Gong Yanping's comment attributes, it is divided into core attributes and secondary attributes [16]. In his research, Li Qigeng divided the comment types into attribute type and perception type [10]. Based on the above, although the classification of comment types is different for different research purposes, it can be roughly divided into rational comments and perceptual comments. The specific classification and characteristics are shown in Table 3.

Table 3 Types of comments and level of interpretation

\begin{tabular}{|c|c|c|c|}
\hline $\begin{array}{c}\text { Comments } \\
\text { on the } \\
\text { classification }\end{array}$ & $\begin{array}{c}\text { The comment } \\
\text { type }\end{array}$ & $\begin{array}{c}\text { Characte } \\
\text { ristics }\end{array}$ & $\begin{array}{c}\text { Interpret } \\
\text { ation } \\
\text { level } \\
\end{array}$ \\
\hline \multirow{6}{*}{ Rational type } & Core attributes & \multirow{6}{*}{$\begin{array}{l}\text { Focus on } \\
\text { the core } \\
\text { attributes, } \\
\text { use } \\
\text { functions, } \\
\text { not easy } \\
\text { to be } \\
\text { affected } \\
\text { by human } \\
\text { factors }\end{array}$} & \multirow{6}{*}{$\begin{array}{l}\text { High level } \\
\text { of } \\
\text { interpretat } \\
\text { ion }\end{array}$} \\
\hline & $\begin{array}{l}\text { Instrumental } \\
\text { review }\end{array}$ & & \\
\hline & Attribute type & & \\
\hline & $\begin{array}{c}\text { Objective } \\
\text { receptive type }\end{array}$ & & \\
\hline & $\begin{array}{l}\text { Attribute based } \\
\text { comments }\end{array}$ & & \\
\hline & Rational type & & \\
\hline \multirow{6}{*}{$\begin{array}{l}\text { Emotional } \\
\text { type }\end{array}$} & $\begin{array}{l}\text { Secondary } \\
\text { attributes }\end{array}$ & \multirow{6}{*}{$\begin{array}{l}\text { It is easy } \\
\text { to be } \\
\text { disturbed } \\
\text { by } \\
\text { emotional } \\
\text { informatio } \\
\mathrm{n} \text { and } \\
\text { human } \\
\text { factors }\end{array}$} & \multirow{6}{*}{$\begin{array}{c}\text { Low level } \\
\text { of } \\
\text { interpretat } \\
\text { ion }\end{array}$} \\
\hline & Identity review & & \\
\hline & Feeling type & & \\
\hline & $\begin{array}{c}\text { Subjective } \\
\text { perception type }\end{array}$ & & \\
\hline & $\begin{array}{l}\text { Comments based } \\
\text { on experience }\end{array}$ & & \\
\hline & Emotional type & & \\
\hline
\end{tabular}

\subsection{Explanation type}

Online comments are an explanation in themselves [17]. A complete and explanatory online comment is divided into: explanation type and explanation content [18]. The interpretation type includes interpretation behavior and interpretation response. Explaining behavior refers to the actions taken by consumers during the purchase process, such as purchase; explanatory response refers to all reactions produced by consumers [17]. Most studies believe that the type of explanation has a greater effect on consumer perception of value than the content of the explanation [12,17]. Therefore, the impact of interpretation types on consumers' purchase intention and value perception has become the focus of research.

\subsection{Information quality}

Information quality refers to the authenticity and reliability of the review content, the relevance of the content to the product it evaluates, and whether it provides a lot of useful information for subsequent purchasers [20]. The quality of information directly determines the value of reviews [21]. Juliet believes that the quality of reviews has a greater impact on consumers' purchase intentions than the ratings of reviewers [22]..

\subsection{Perceived similarity}

Perceived similarity refers to the degree of similarity that people believe in themselves and others. When the perceptual similarity is high, people tend to have stronger attraction [23]. Most mainstream articles believe that the persuasive power of high similarity is greater than the persuasive power of low similarity, but Zhang Qin and other studies believe that when the product recipient changes, the recipients with a longer psychological distance will be affected by comments with low similarity [13] ]. In summary, the closer the psychological distance, the higher the perceived similarity. This kind of high perceived similarity is conducive to enhancing the trust of consumers and reducing their uncertainty in decisionmaking.

\section{Conclusion}

In recent years, although the research in this field has developed rapidly and has become more popular, there are still some research deficiencies and limitations.

1. When the actual spatial distance cannot be changed, from which aspects and measures should be taken to shorten the spatial distance in terms of perception, enhance consumer perception of value, and effectively compensate and enhance consumers' perception of value of the review content under the actual long spatial distance, Can become a new research direction.

2. In hypothetical research, compared with other psychological distances, hypothetical, the difference between real and imagined objects, and the difference between possible events and impossible events are the most important [7]. How consumers perceive risks, and what kind of influence will they have on purchase intentions and purchase behaviors, still have research value.

3. The information quality of the review content will inevitably affect consumers' purchase intentions, and compared with other factors, the impact of information quality is more significant and direct. However, there is no uniform standard for the quality of online review information for different product types and consumers in existing research. Will this difference have a different impact on review readers?

4. Existing studies generally believe that the type of 
explanation has a greater impact on consumers' purchase intentions than the content of the explanation, but how to play the role of the content of the explanation, thereby enhancing the overall impact of reviews, is worthy of further study.

\section{References}

1. Li X X, Hitt L M. Self-selection and Information Role of Online Product Reviews [J]. Information Systems Research, 19(4):456-474(2008)

2. Bright local Local Consumer Review Survey [EB/OL]. [2018-12-07]https: // www.brightlocal. com/research/local-consumer-review-survey/

3. Dong Shuang, Wang Xiaohong, Ge Zhenghong. Analysis of online comment content characteristics of B2C shopping websites based on text mining [B]. Library Theory and Practice. 54-58(2017)

4. Lee K Y, Yang S B. The role of online product reviews on information adoption of new product development professionals [J] Internet Research, 25(3):435452(2015)

5. Duan Wenjing, CaoQing, GanQiwei. Investigatingde - terminants of voting for the "Helpfulness" of online consumer reviews: A text mining approach[J]. Decision Support Systems, 50(2):511-521(2011)

6. Yaacov Trope, Nira Liberman, Cheryl Wakslak. Construal Levels and Psychological Distance: Effects on Representation, Prediction, Evaluation, and Behavior[J]. Journal of Consumer Psychology, 17(2):83-95(2007)

7. Trope Y, Liberman N, Wakslsk C. Construal Levels and Psychological Distance: Effects on Representation, Prediction, Evaluation, and Behavior [J]. Journal of Consumer Psychology, 17(2):8395(2007)

8. Li Ang, Zhao Zhijie. A review of research on the usefulness of online reviews. Business Economics Research [A]. 77-80(2019)

9. Li Zehua. Research on the Moderating Variables of the Influence of Hotel Early Online Reviews on Follow-up Reviews. Harbin Institute of Technology. (2016)

10. Li Qigeng, Zhao Xiaohong, Yu Mingyang. The influence of information characteristics of online reviews of service-oriented products on the perceived usefulness and purchase intention of reviews [A]. Industrial Engineering and Management. 22(6): 148153(2017)

11. Zhou Meihua, Li Peihua, Mou Yupeng. The influence of online reviews on consumers' purchase intentionsthe mediating role of psychological distance[A]. Marketing and Service. 29(1): 101-109(2015)

12. Li Baoku, Guo Tingting. The impact of interpretation types on the perceived usefulness of online reviews from the perspective of two-stage decision-making [A]. Journal of Central University of Finance and
Economics. 2:119-128(2019)

13. Zhang Qin, Gong Yanping, Zhang Xiaodan. Shopping for others: What is the difference in the persuasiveness of online reviews? [J]. Management Review. 31(2): 94-102(2019)

14. Luo Weipeng. Research on the impact of psychological distance on the usefulness of virtual community word-of-mouth: Taking college students in Shandong Province as an example [D]. Qingdao: China University of Petroleum. (2017)

15. Che Cheng, Luo Weipeng, Qi Xiaolin. The influence of space and social distance on the valence of online word-of-mouth in virtual communities [A]. Soft Science. 1001-8409. (2017)

16. Gong Yanping, Huang Kai, Zhang Qin, Gu Hongping. Research on the relationship between the time distance of new product announcements, consumer online reviews and their purchase goals[A]. Research and Development Management. 27(4):36-44(2015)

17. Wang Xuhui, Nie Keyu, Chen Rong. "Explain the behavior" or "explain the response"? What kind of online reviews are more useful---The influence and boundary conditions of online reviews based on interpretation types on consumer purchasing decisions[A]. Nankai Management Review. 20(4): 27-37(2017)

18. Moore S G. Attitude Predictability and Helpfulness in Online Reviews: The Role of Explained Actions and Reactions [J]. Journal of Consumer Research, 42(1): $30-44(2015)$

19. Chan H. Adaptive Word-of-mouth Behavior: A Conceptual Framework and Empirical Tests [D]. Madison: The University of WisconsinMadison.(2000)

20. Zhang Yanhui, Li Zongwei, Zhao Yicheng. The impact of information quality based on Taobao comment data on the usefulness of online comments [A]. Journal of Management. 14(1): 77-85(2017)

21. Zheng Xiaoping. An Empirical Study on the Influence of Online Reviews on Online Consumers' Purchase Decisions [D] . Master's thesis of Renmin University of China,(2008)

22. Zhu Liye, Yuan Denghua, Zhang Jingyi. The influence of online user review quality and reviewer rating on consumer purchase intention-the moderating effect of product involvement[J].Management Review. 29(2): 8996(2017)

23. Montoya R M, Horton R S, Kirchner J. Is Actual Similarity Necessary for Attraction? A Meta-analysis of Actual and Perceived Similarity [J].Journal of Social and Personal Relationships, 25(6):889-922. 2008 